\title{
Quantifying the influence of sub-mesoscale dynamics on the supply of iron to Southern Ocean phytoplankton blooms
}

\author{
Isabella Rosso ${ }^{\mathrm{a}, \mathrm{d}, \mathrm{e}, *}$, Andrew McC. Hogg ${ }^{\mathrm{a}, \mathrm{e}}$, Richard Matear ${ }^{\mathrm{b}, \mathrm{e}}$, \\ Peter G. Strutton ${ }^{\mathrm{c}, \mathrm{e}}$ \\ ${ }^{a}$ Research School of Earth Sciences, The Australian National University, Canberra, \\ Australia \\ ${ }^{b}$ Centre for Australian Weather and Climate Research, CSIRO Marine and Atmospheric \\ Research, Hobart, Australia \\ ${ }^{c}$ Institute for Marine and Antarctic Studies, University of Tasmania, Hobart, Australia \\ ${ }^{d}$ CSIRO Wealth from Oceans Research Flagship, Hobart, Tasmania, Australia \\ ${ }^{e} A R C$ Centre of Excellence for Climate System Science
}

\begin{abstract}
Southern Ocean phytoplankton growth is limited by iron. Episodes of natural iron fertilisation are pivotal to triggering phytoplankton blooms in this region, the Kerguelen Plateau bloom being one prominent example. Numerous physical mechanisms that may supply iron to the euphotic zone in the Kerguelen Plateau region, and hence triggering a phytoplankton bloom, have been identified. However, the impact of sub-mesoscale flows in delivering iron have been omitted. With a scale of order $10 \mathrm{~km}$, sub-mesoscale filaments and fronts can dramatically increase vertical velocities and iron transport.

An innovative technique is developed to investigate the role of vertical advection associated with sub-mesoscale features on the supply of iron to the photic zone. First, Lagrangian trajectories are calculated using three dimensional velocity fields from high resolution numerical simulations; iron concentration is then computed along these Lagrangian trajectories. The contribution of mesoscale- $\left(1 / 20^{\circ}\right.$ resolution $)$ and sub-mesoscale-resolving models $\left(1 / 80^{\circ}\right.$ resolution) is compared, thereby revealing the sensitivity of iron supply to hori-
\end{abstract}

\footnotetext{
*Corresponding author

Email address: isa.rosso@anu.edu.au (Isabella Rosso)
}

Preprint submitted to Deep-Sea Research Part I

May 20, 2016 
zontal resolution. Iron fluxes are clearly enhanced by a factor of 2 with the resolution, thus showing that the vertical motion induced by the sub-mesoscales represents a previously neglected process to drive iron into the photic waters of the Kerguelen Plateau.

\section{Introduction}

The Southern Ocean has a profound influence on the past, present (e.g. Mayewski et al., 2009) and future (e.g Takahashi et al., 2012) climate system. In this region, energetic mesoscale eddies and jets of the Antarctic Circumpolar Current (ACC) act to redistribute heat and mix water properties between the Atlantic, Pacific and Indian ocean basins. Furthermore, the Southern Ocean is the nexus of the meridional overturning circulation, where dense waters originating from the North Atlantic upwell and split into two directions: northward, where they become fresher and warmer and are subducted again forming the Antarctic Intermediate Water, or southward where their increase in density drives the formation and sinking of the world's densest water, Antarctic Bottom Water (e.g. Marshall and Speer, 2012; Talley, 2013). The Southern Ocean, thereby, helps to drive the global ocean circulation, and stores and recirculates heat, carbon and other gases, such as oxygen, exchanged with the atmosphere.

The Southern Ocean accounts for a substantial portion of the global sequestration of anthropogenic carbon dioxide (e.g. Khatiwala et al. (2009) estimated that the Southern Ocean contributed for over $40 \%$ of the oceanic uptake of anthropogenic $\mathrm{CO}_{2}$ in 2008). The Southern Ocean is also important to the global carbon cycle and it is implicated in the large glacial to interglacial changes in atmospheric $\mathrm{CO}_{2}$ (Sigman et al., 2010). Several processes impact the carbon cycle in the oceans, such as the biological and solubility pumps (e.g. Ducklow et al., 2001), as well as physical mechanisms active at regional scales such as upwelling and subduction (e.g. Marshall and Speer, 2012). In light of the Southern Ocean's primary role in influencing the carbon cycle, precise quantification of the individual processes that control carbon cycling in this region is critical 
for understanding and predicting our future climate.

Phytoplankton production is one process that has a direct impact over the export of carbon. However, in much of the Southern Ocean the phytoplankton activity is limited by the availability of iron (Boyd et al., 2000; Coale et al., 2004; De Baar et al., 2005). Martin (1990) hypothesised that iron can stimulate phytoplankton productivity and thereby contribute to a drawdown of atmospheric $\mathrm{CO}_{2}$. Understanding the potential iron sources and physical mechanisms that can supply iron into the surface waters (and trigger a phytoplankton response) is therefore a prerequisite to understanding Southern Ocean phytoplankton blooms.

One of the largest regular phytoplankton blooms occurs in the Kerguelen Plateau (KP) region of the Southern Ocean. Recent studies have identified several physical mechanisms controlling dissolved iron delivery during the growth and evolution of the KP phytoplankton bloom. Iron input can come from aeolian dust deposition (Bucciarelli et al., 2001; Chever et al., 2010) or sediments, which can enter KP sunlit waters transported by the stirring action of eddies (Abraham et al., 2000; d'Ovidio et al., 2013), turbulent mixing due to tides and internal waves (Park et al., 2008), wind-induced upwelling (Gille et al., 2014) or lateral advection (Van Beek et al., 2008; Mongin et al., 2009) and mixing (Maraldi et al., 2009). However, calculations of the quantity of iron required to sustain the Kerguelen Plateau bloom indicate that additional iron is required (Bowie et al., 2014).

It was recently proposed that sub-mesoscale dynamics (defined by a length scale less than $10 \mathrm{~km}$ and Rossby number greater than 1) could be an important supply of iron to the KP region (Rosso et al., 2014). The rich mesoscale eddy field (with length scales of $O(100 \mathrm{~km})$ ) gives rise to strong sub-mesocales velocities in the Kerguelen Plateau region (Rosso et al., 2015) and which can dramatically increase vertical velocities and transport of particles (Rosso et al., 2014). Lévy et al. (2001) showed that sub-mesoscales can increase the nutrient vertical transport and consequently influence biological cycles in other parts of the ocean. In this study we aim to contrast the effect of sub-mesoscales against 
mesoscale (and larger scales) on iron transport.

Our approach is a numerical study of the dissolved iron concentration $(\mathrm{DFe})$ and is based on the development of a mathematical model $\left(\right.$ FeRRO $\left._{S O}\right)$, that associates the computation of DFe to Lagrangian particles, advected by a series of three dimensional high-resolution models of the Kerguelen Plateau region. We highlight that the Lagrangian framework could be employed with the formulation of a parameterization for diffusive processes. However, in our approach we do not include this diffusive part (which can be added in the Lagrangian framework in the form of a random component), but focus only on advection. To correctly include diffusive processes from the Eulerian model, it would have been appropriate to employ passive tracer experiments, on-line with the physical Eulerian model. However, this would have required a reliable coupled bio-geochemical component to be added to the physical model, and a large computational cost. Complex biogeochemical models, which include iron dynamics, have been applied at a coarser resolution (e.g. Archer and Johnson, 2000; Gregg et al., 2003), and therefore have not resolved sub-mesoscale processes. Other modelling studies, run at higher resolution and therefore able to resolve smaller structures, omitted the vertical dimension and only focused on the role of horizontal transport (e.g. Mongin et al., 2008; d'Ovidio et al., 2015). Our model includes sub-mesoscale processes with 3D circulation, which is a significant improvement in representing the ocean dynamics, but uses a simple iron model which only considers the advective processes.

The Lagrangian framework is reported in section 2, while FeRRO $S O$ is described in section 3). We perform a sensitivity analysis on FeRRO (subsection 3.2) and investigate iron fluxes in mesoscale- and sub-mesoscaleresolving models (section 4). The implications of these calculations are discussed in section 5 . 


\section{Sub-mesoscale impact on Lagrangian paths}

Numerical simulations of the ocean circulation around the Kerguelen Plateau have been run using the MITgcm of Marshall et al. (1997), forced and relaxed by temporally constant fields (wind, fresh water fluxes, temperature and horizontal velocities from the Southern Ocean State Estimate of Mazloff et al. (2010)). The model is implemented at two horizontal resolutions: first, at $1 / 20^{\circ}$ resolution in order to capture the circulation with scales down to the mesoscales, and second, at $1 / 80^{\circ}$ resolution to explicitly include sub-mesoscales. Both models have 150 vertical layers, with a vertical resolution varying from $10 \mathrm{~m}$ in the upper layers to $50 \mathrm{~m}$ near the bottom. The sub-mesoscale resolving model $\left(1 / 80^{\circ}\right)$ is nested in the $1 / 20^{\circ}$, relaxed to the $1 / 20^{\circ}$ horizontal velocity, salinity and temperature at the northern and southern boundaries and at the surface. The model outputs include velocity, temperature, salinity and density fields. A more detailed description of the implementation, discussion and assessment of these experiments have been outlined in two previous works and the reader is referred to them (Rosso et al., 2014, 2015).

Rosso et al. $(2014,2015)$ showed an energetic sub-mesoscale field downstream of the plateau, likely due to the destabilisation of the Antarctic Circumpolar Current interacting with the topography. Sub-mesoscales increase the magnitude of the eddy kinetic energy (Rosso et al., 2014), when compared to the mesoscale-resolving model and to a regional high-resolution altimetry product from AVISO (not shown).

In the present work, we aim to show that the rich sub-mesoscale dynamics can enhance the vertical supply of nutrients, compared with mesoscale and larger scale dynamics. We here use a similar approach to Rosso et al. (2014), implementing a set of Lagrangian particle-tracking experiments (reported below) to contrast the mesoscale- to the sub-mesoscale-driven vertical transport. These experiments are then used as foundation for the development of $\mathrm{FeRRO}_{S O}$. 


\subsection{Lagrangian trajectories}

The Connectivity Modelling System (CMS) of Paris et al. (2013) is used offline, to integrate Lagrangian particle trajectories using daily-snapshot velocity fields from the numerical simulations. The procedure followed is to seed regions of interest with a constant density of Lagrangian particles. The CMS software is then used to integrate the trajectory of these particles backwards in time. Given a sufficiently large number of particles, this technique informs us of both the sources of water and the path followed.

Particles are released in two different regions (boxes $R_{1}$ and $R_{2}$ in Fig. 1) chosen in order to isolate locations of diverse phytoplankton activity (Fig. 1b) and with differing intensity of sub-mesocale flows (Fig. 1c). As reference for the phytoplankton activity, we considered the satellite-derived chlorophyll map taken during the 2011 KEOPS2 experiment (Fig. 6 of Park et al. (2014)). This map shows three major peaks in the chlorophyll concentration, which are linked to different circulations around and over the plateau (Fig. 15 of Park et al. (2014)). Then, by comparing our modelled circulation with their observations, we chose areas with moderate to high chlorophyll and weak $\left(\mathrm{R}_{1}\right)$ or strong $\left(R_{2}\right)$ sub-mesoscale vertical velocities. $R_{1}$ is located at $71^{\circ} \mathrm{E}-72^{\circ} \mathrm{E}, 46.5^{\circ} \mathrm{S}-$ $49^{\circ} \mathrm{S}$, designed to capture the bloom observed near the plateau, which occurs in a region of relatively weak sub-mesoscale activity. Region $R_{2}$, located at $74^{\circ} \mathrm{E}-76^{\circ} \mathrm{E}, 47^{\circ} \mathrm{S}-49^{\circ} \mathrm{S}$, encompasses a region of an observed phytoplankton bloom downstream of the plateau, where intense sub-mesoscales dominate the circulation.

A total of 2142 and 3362 particles have been initialised in regions $R_{1}$ and $R_{2}$ respectively. Particles have been released in each box over 2 different depths (75 $\mathrm{m}$ and $200 \mathrm{~m}$ ) and equally spaced in the longitudinal and latitudinal directions, with a step of $0.05^{\circ}$ in both directions. The release depths have been chosen in order to capture levels below and within the spatial mean mixed layer depth of that area (we estimated maximum spatial means of mixed layer depths of approximately $84 \mathrm{~m}$ and $113 \mathrm{~m}$ for the two regions in the $1 / 20^{\circ}$ model and $131 \mathrm{~m}$ and $152 \mathrm{~m}$ in the $1 / 80^{\circ}$ areas, at the time of release). It is at the deeper 


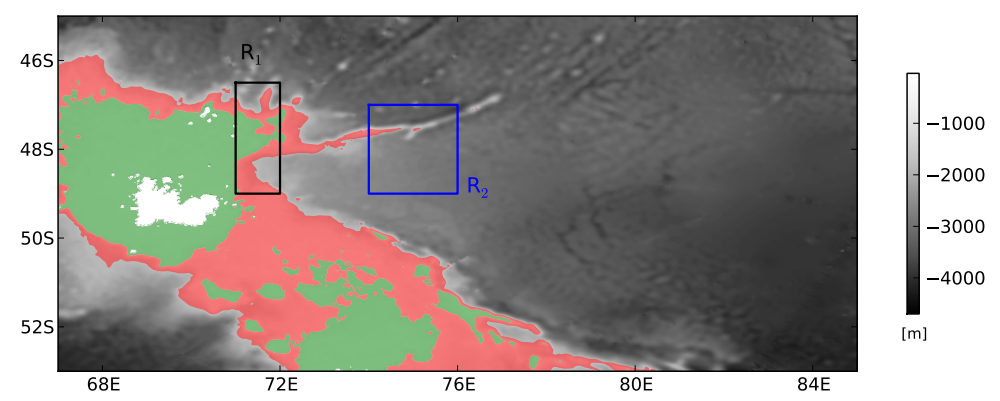

(a)

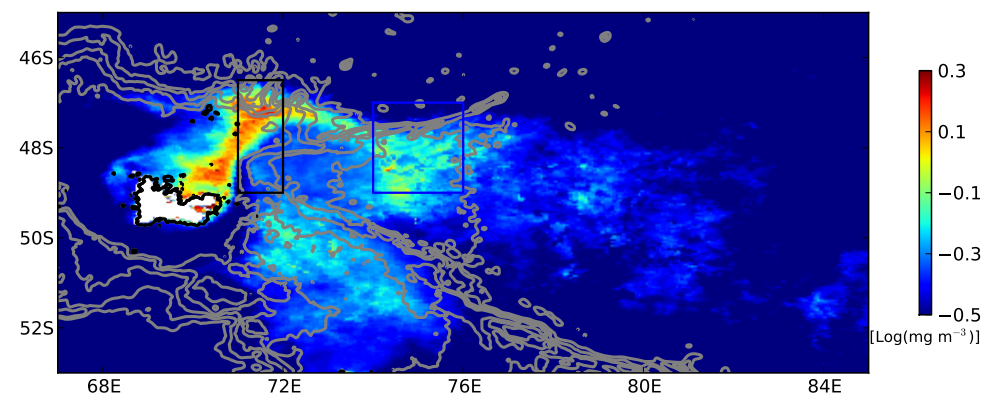

(b)

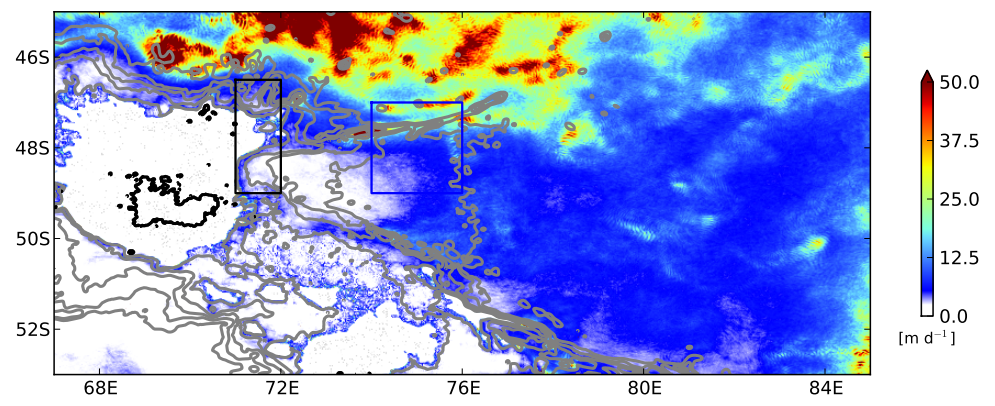

(c)

Figure 1: (a) Kerguelen Plateau bathymetry. In green the area $O N$ the plateau (defined by the $500 \mathrm{~m}$ isobath); in red is the transition zone, between the $O N$ and $O F F$ plateau area (grey shading, delimited by the $1500 \mathrm{~m}$ isobaths). (b) November 2011 chlorophyll a concentration (data are taken from Aqua MODIS $4 \mathrm{~km}$ and expressed as base 10 logarithm). (c) Two hundred day temporal averages of the magnitude of sub-mesoscale vertical velocity at $400 \mathrm{~m}$ (color scale is saturated). The black and blue boxes in each panel delineate the particle release locations.

143 level, i.e. at $200 \mathrm{~m}$, that the quantification of the vertical advective flux of 144 iron is significant for the investigation of the meso- and sub-mesoscale flows. 
In order to explore how meso- and sub-mesoscales influence the transport of water particles, no turbulent scheme has been employed; Lagrangian particles are purely advected by daily snapshots of zonal, meridional and vertical velocity dataset. The robustness of the daily sampling has been tested in our previous work (Rosso et al., 2014), using model output sampled between three hours and two days. A timestep of 60 seconds is implemented over a maximum integration time of 200 days, with outputs saved every 12 hours. The specific integration time varies for each particle: it is less than 200 days in case the particle exit a defined domain of analysis (which extends up to $68^{\circ} \mathrm{E}$ and between $52^{\circ} \mathrm{S}-42^{\circ} \mathrm{S}$ ).

We define two water sources: $O N$ and $O F F$ the plateau. We base this distinction on the observational study of Blain et al. (2007), in which their stations $O N$ the plateau were those in water depth of less than $500 \mathrm{~m}$ and $O F F$ the plateau included those with a depth exceeding $1500 \mathrm{~m}$. The distinction is based on the observation of different profiles of $D F e$, highlighting that a spatial dependence on $D F e$ pools exists in the Kerguelen Plateau region. Thus, we identify the $500 \mathrm{~m}$ isobath as the limit for our $O N$ area (green region in Fig. 1a). Beyond this, an $O F F$ plateau region is defined, which includes a transition zone between the $O N$ area and the $1500 \mathrm{~m}$ contour (red shaded area in Fig. 1a).

At $1 / 20^{\circ}$ resolution, we found that waters originating from the plateau $(O N)$ account for the $59 \%$ and $22 \%$ in case of $R_{1}$ and $R_{2}$, respectively. At $1 / 80^{\circ}$ resolution, the $O N$ particles account for the $75 \%\left(R_{1}\right)$ and $32 \%\left(R_{2}\right)$. This result highlights, first, that water sources are sensitive to the horizontal resolution and, second, that water sources differ between the two regions under analysis.

Figure 2 shows several selected example Lagrangian trajectories for the $1 / 80^{\circ}$ resolution experiment (plotted are daily particle positions color-coded depending on the daily particle depth). Release and source positions of the particles are shown by circular and triangular markers, respectively (recalling that trajectories are integrated backwards in time). We highlight a range of different trajectories, including those crossing the plateau either north or south of the Kerguelen Island, as reported by Rosso et al. (2014), and deep trajectories coming from the south east region of the plateau (Fig. 2), likely captured by the 
Donohue, 2007).
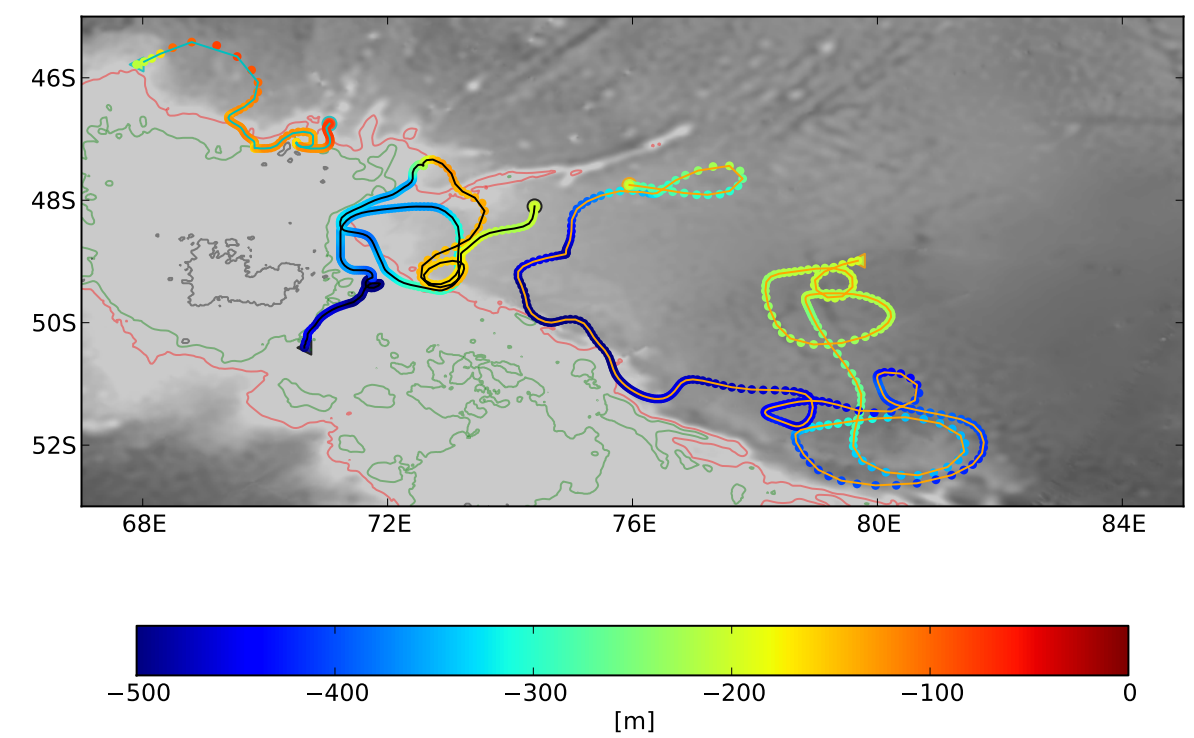

Figure 2: Examples of Lagrangian trajectories, daily sampled, color-coded depending on the daily depth, for the $1 / 80^{\circ}$ resoluton experiment. Circular markers indicate the particle release location, while triangular the source position. Topography is shaded in grey. Green contours indicate the boundaries of the $O N$ source, while red the $O F F$ plateau source.

deep western boundary current on the east flank of the plateau (McCartney and

\subsection{Depth distribution of tracked particles}

The particle distribution in the water column, computed as a probability density function (PDF) of the source particle as a function of depth, over each region, is shown in Fig. 3. The PDFs are computed for the total particles released at both $75 \mathrm{~m}$ and $200 \mathrm{~m}$ and show the distribution for $O N$ (dashed lines), OFF (dotted) and all particles (solid) for each region. The double peaks in each profile in Fig. 3 is due to the particles being released at the two initial depths. The $1 / 20^{\circ}$ resolution profiles are shown in red, while the $1 / 80^{\circ}$ are in black. For each region, the PDF profiles are normalised to $\sum_{i=1}^{N} T_{i}$, where $N$ refers to either the total number of $O N$ or $O F F$ particles, or to the total number of particles released in the region. $T_{i}$ indicates the lifespan of the particle $i$, which 

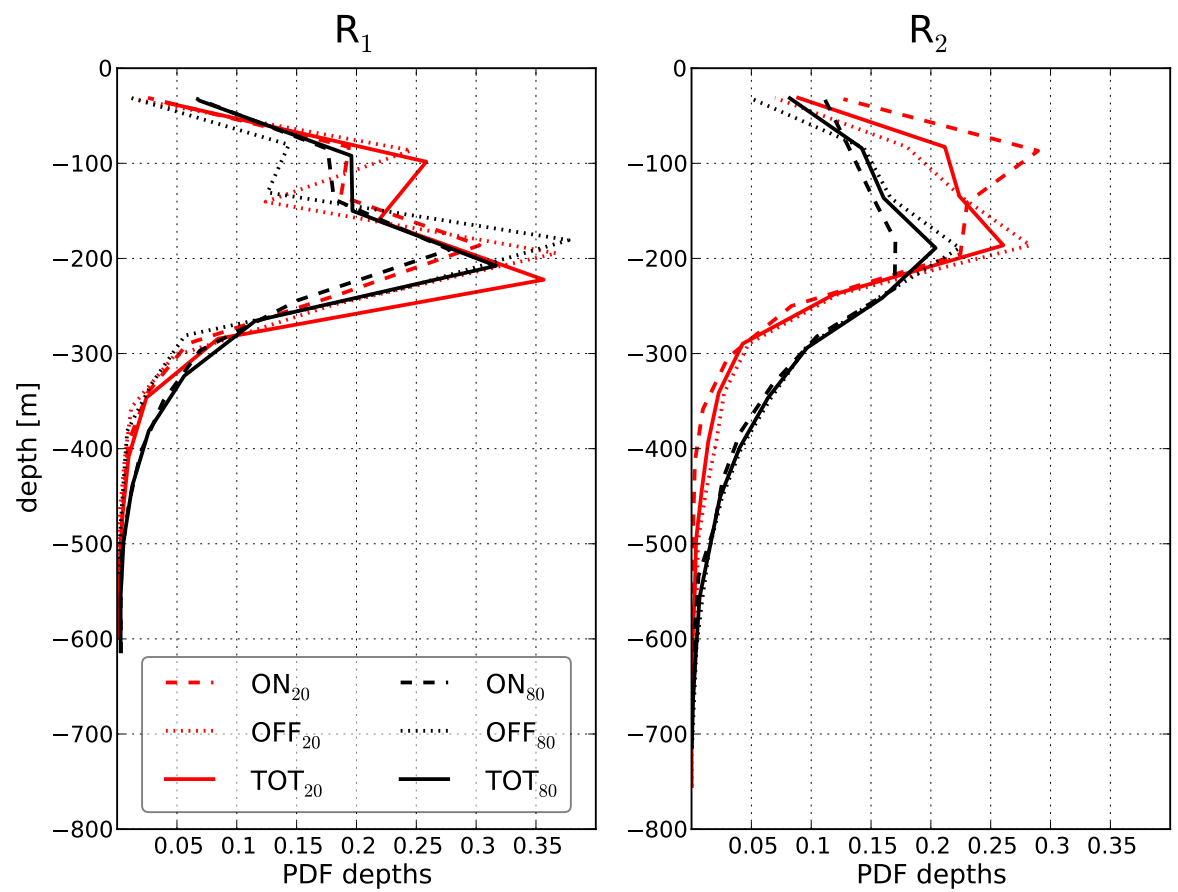

Figure 3: Probability density function of particle depth for the two regions of investigation, $\mathrm{R}_{1}$ and $R_{2}$. The statistics has been computed considering the experiments with the two depths of release $(75 \mathrm{~m}$ and $200 \mathrm{~m})$ together. Colors indicate the different resolution (red is for the $1 / 20^{\circ}$ and black is for the $1 / 80^{\circ}$. Dashed lines are the profiles for the $O N$ particles, dotted for the $O F F$ and solid for the total amount of particles $(T O T)$. $O N$ the plateau particles are those found in water depth of less than $500 \mathrm{~m}$, while $O F F$ the plateau include those with a depth exceeding $1500 \mathrm{~m}$.

can be less than the total integration time of 200 days, as the particle can exit the model domain or reach land in less than 200 days. The figure shows that the impact of the horizontal resolution on the PDF profiles for the two regions of interest depends on the location of analysis and on the range of depths considered. For region $\mathrm{R}_{1}$, the PDF profiles are not significantly influenced by resolution. Furthermore, the mean depth of the total PDF profiles in $\mathrm{R}_{1}$ (approximately $130 \mathrm{~m}$ at $1 / 20^{\circ}$ resolution and $171 \mathrm{~m}$ at $1 / 80^{\circ}$ ) are shallower than the mean depth in $\mathrm{R}_{2}$ (approximately $163 \mathrm{~m}$ at $1 / 20^{\circ}$ and $191 \mathrm{~m}$ at $1 / 80^{\circ}$ ), suggesting that $R_{1}$ is a region with a higher probability of surface-sourced particles. On the contrary, there is a larger number of deep-sourced particles in $R_{2}$, which 
increases with the resolution. The larger number of particles found at depths below $300 \mathrm{~m}$ in $\mathrm{R}_{2}$ is not surprising when considering that the deep reaching sub-mesoscale activity present in this region cycles the water as deep as $1000 \mathrm{~m}$ Rosso et al. (2014), and this is much stronger in the $1 / 80^{\circ}$ simulation than in the $1 / 20^{\circ}$.

\section{Methods}

We here describe the off-line model that has been implemented in order to compute the evolution of iron concentration on the trajectories of Lagrangian particles.

\subsection{FeRROSO}

Iron concentration is computed by implementing a decay/replenishment model. This methodology has the advantage of being simple and easy to modify and discriminate the role of specific physical processes. Input of the model is a 3D position as a function of time. At each instant, FeRRO ${ }_{S O}$ estimates the concentration of iron for the $i$-th particle $\left(D F e_{i}\right)$ by solving the following equation:

$$
D \dot{F} e_{i}=-\lambda\left(z_{i}\right) D F e_{i}-f\left(z_{i}\right)\left(D F e_{i}-\langle D F e\rangle_{i}\right),
$$

where $D \dot{F} e_{i}$ represents the time derivative of $D F e_{i}$. Parameters of (1) represent decay $(\lambda)$ and replenishment $(f)$ of iron. Replenishment occurs via restoring towards $\langle D F e\rangle_{i}$, a $3 \mathrm{D}$ function describing the temporal mean concentration of iron taken from climatology. Each of these terms are discussed in the following subsections. Three layers are identified in the model, with differing behaviours, whose boundaries are the surface, $z_{1}=-100 \mathrm{~m}, z_{2}=-200 \mathrm{~m}$ and the bottom depth. (Note that depths $z$ are defined negative in all the calculations throughout the paper).

\subsubsection{Decay rate}

In the upper region $\left(z_{i} \geq z_{1}\right) D F e_{i}$ is constrained to decay with rate $\lambda(z)$. This decay rate $\lambda$ (given in day $^{-1}$ ) depends exponentially on depth and is used 

$\lambda_{0}=(0.004, \mathbf{0 . 0 1 5}, 0.03) \mathrm{day}^{-1}$ (the bold value indicates our reference case).

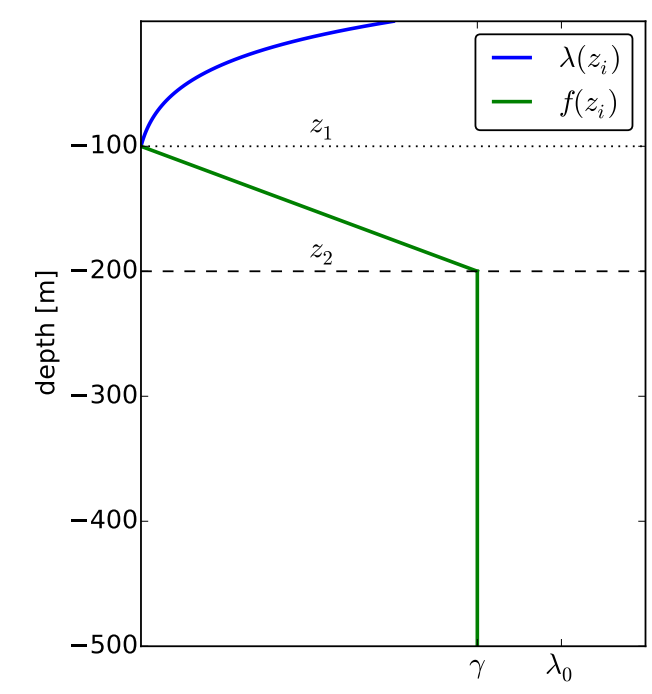

(a)

$$
\lambda\left(z_{i}\right)=\lambda_{0} \frac{z_{i}-z_{1}}{z_{1}} e^{\frac{z_{i}}{\delta}}
$$

The vertical profile in (2), shown by the blue line in Fig. 4a, has been chosen in order to take into account the depth-dependent consumption of iron, associated with light irradiance (note that $\lambda=0$ for depths $z_{i}<z_{1}$ ). Mongin et al. (2009) estimated an optimal annual averaged decay rate at the surface of 0.015 day $^{-1}$. We test the sensitivity of dissolved iron concentration to the decay rate, with

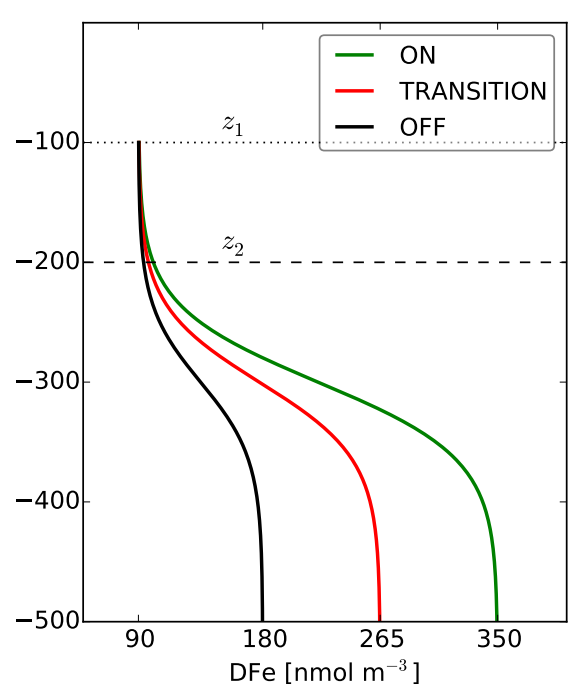

(b)

Figure 4: (a) Vertical profiles of (blue) decay rate $\lambda\left(z_{i}\right)$ from equation (2) and (green) structure function $f\left(z_{i}\right)$ for the relaxation term (3). (b) Vertical profiles of $\langle D F e\rangle_{i}$ as computed by solving (4), for the $O N$ (green line) and $O F F$ (black) the plateau areas, and in the transition zone (red) (for clarity, only the first $500 \mathrm{~m}$ are shown). 


\subsubsection{Replenishment rate}

The second term in the RHS of equation (1) determines the relaxation of $D F e_{i}$ to the particle background mean concentration $\langle D F e\rangle_{i}$, whose value depends on the location of the particle. The timescale of the replenishment is governed by a structure function, $f\left(z_{i}\right)$. The function $f\left(z_{i}\right)$ (green line in Fig. 4a) depends on a timescale $\gamma$ (units are day ${ }^{-1}$ ) and depth $z_{i}$, as:

$$
f\left(z_{i}\right)=\left\{\begin{array}{lr}
\gamma & z_{i} \leq z_{2} \\
\frac{\gamma\left(z_{i}-z_{1}\right)}{z_{2}-z_{1}} & z_{1}<z_{i}<z_{2} \\
0 & z_{i} \geq z_{1}
\end{array}\right.
$$

We allow a replenishment only at depths $z_{i}<z_{1}$ : replenishment is thus distinct from the loss of iron to primary productivity in the euphotic zone. We vary the replenishment timescale $\tau=1 / \gamma$ from a minimum of 0.1 days to 10 days $(0.1$, $0.2,0.5, \mathbf{1}, 5,10)$.

\subsubsection{Mean concentration of DFe}

Below $z_{1}$, the $i$-th particle is relaxed to a mean $(\langle\cdot\rangle)$ concentration that depends on its relative position to the plateau and on its depth (Fig. 4b):

$$
\langle D F e\rangle_{i}=A-B \tanh \left(-\frac{300+z_{i}}{z_{2}} \pi\right),
$$

where $A=\frac{\max (\langle D F e\rangle)+\min (\langle D F e\rangle)}{2}$ and $B=\frac{\max (\langle D F e\rangle)-\min (\langle D F e\rangle)}{2}$. The minimum value of $\langle D F e\rangle$ in parameters $A$ and $B$ is defined as $90 \mathrm{nmol} \mathrm{m}^{-3}$, everywhere in the domain (based on the measured mixed layer value found by Blain et al. (2007)). The maximum value depends on the horizontal location of the particle. Based on observed mean concentrations of DFe at depth (Blain et al., 2007), we define a value of $350 \mathrm{nmol} \mathrm{m}^{-3}$ as $\max (\langle D F e\rangle)$ in the $O N$ region and $180 \mathrm{nmol} \mathrm{m}^{-3}$ as $\max (\langle D F e\rangle)$ in the $O F F$ region. In the transition zone, we choose a maximum value given by the middle point between the two maximum concentrations in the $O N$ and $O F F$ regions. 
The profile in (4) has been chosen to idealise the profile in Figure 2 of Blain et al. (2007) and to consider a ferricline, or the depth where the vertical gradient of $D F e$ is maximum (Tagliabue et al., 2014), of $300 \mathrm{~m}$. This value has been chosen in order to follow the result reported in Tagliabue et al. (2014) for the mean depth of the ferricline in the Southern Ocean, and in particular for the Kerguelen Plateau region (their Fig. 1a). Furthermore, for depths above or equal to $z_{1}$ it is clear from (1) that the dissolved iron concentration reaches a zero steady state solution. This approach has been chosen in order to focus solely on advective processes as mechanisms of supply of $D F e$.

\subsubsection{Initialisation of $\mathrm{DFe} e_{i}$}

The initial value of iron concentration depends on the depth of the particle: if deeper than $z_{1}$, it is initialised to $\langle D F e\rangle_{i}$ from equation (4), otherwise its initial value is zero. This formulation has been chosen in order to isolate deep sources of dissolved iron and how the different flows influence its transport from depth.

\subsection{Sensitivity to FeRROSO parameters}

The FeRRO ponents of advective transport of tracers in a complex three dimensional flow field. Before using the model, we first explore the sensitivity of $\mathrm{FeRRO}_{S O}$ to a range of values of the governing parameters: the decay and replenishment rates (listed in sections 3.1.2 and 3.1.3 respectively). Note that a sensitivity analysis on the mean concentration term is not necessary, as the results scale linearly with $\langle D F e\rangle_{i}$.

We focus on the total concentration of iron, as defined by equation (5) below, and on upwelling iron fluxes, computed as mean of local fluxes $w_{i} \cdot D F e_{i}$, where $w_{i}$ is the upward vertical velocity of the $i$-th particle at the release time and location). The average concentration of iron is estimated as

$$
[D F e]=\frac{\sum_{i=0}^{N}\left[D F e_{i}\right] \cdot d V_{i}}{V}
$$


where $\left[D F e_{i}\right]$ is the concentration of the $i$-th particle, computed at the seeding position occupied by the $i$-th Lagrangian particle. $d V_{i}$ is the volume of the particle $i$ at this location: we highlight that $d V_{i}$ is valid only at the very moment of seeding, as this is the only instant in time where we can define a representative volume for each particle. At this instant, $d V_{i}=d x_{i} \cdot d y_{i} \cdot d z_{i}$, where the increment in the longitude direction $\left(d x_{i}\right)$ is a function of latitude $y_{i}$ (as our ocean circulation models use spherical coordinates) and varies between approximately $3580 \mathrm{~m}$ and $3830 \mathrm{~m}$. Increments in latitude and depth are: $d y_{i}=5560 \mathrm{~m}$ and $d z_{i}=125 \mathrm{~m}$, for each particle. Finally, $V$ represents the total volume occupied by the particles: $V=\sum_{i=0}^{N} d V_{i}$. Note that for this calculation we evaluated a mean of both particles initialised at $75 \mathrm{~m}$ and $200 \mathrm{~m}$, excluding those whose vertical displacement never exceeds $z_{1}$.

The sensitivity is shown in Fig. 5: the left panel shows the sensitivity to the decay rate $\lambda$, with the dependence on the replenishment timescale $\tau$ on the right. Results show the difference from the reference case expressed as a percentage of $[D F e]$ (panels a,b) and of $w \cdot D F e(\mathrm{c}, \mathrm{d})$. Results from the two regions are presented: black lines are for $\mathrm{R}_{1}$, blue for $\mathrm{R}_{2}$. FeRRO $\mathrm{FO}_{S O}$ is not significantly sensitive to the chosen values of $\lambda$, in both regions: we can estimate a maximum change in $[D F e]$ of less than $\pm 1 \%$ in both $\mathrm{R}_{1}$ and $\mathrm{R}_{2}$. The sensitivity to the timescale of relaxation $\tau$ is also weak, giving approximately $\pm 3 \%\left(\mathrm{R}_{1}\right)$ and $\pm 4 \%$ $\left(R_{2}\right)$. The change in vertical fluxes (Fig. 5c) shows a larger sensitivity to the change of $\lambda$, of approximately $\pm 2 \%$ in $R_{1}$ and $\pm 1.5 \%$ in $R_{2}$, while the sensitivity to the timescale is weaker, with a maximum change of less than $\pm 1 \%\left(R_{1}\right)$ and $\pm 3 \%\left(\mathrm{R}_{2}\right)$ (Fig. $\left.5 \mathrm{~d}\right)$.

The results reported here are for the highest resolution case, however, we found similar sensitivity for the $1 / 20^{\circ}$ experiment. We conclude that the sensitivity of $\mathrm{FeRRO}_{S O}$ to the choice of parameters is weak, which might indicate that the transition of the particles in the water column due to the advective contribution of mesoscale and sub-mesoscale flows act on timescales faster than the decay and restoring rates. 


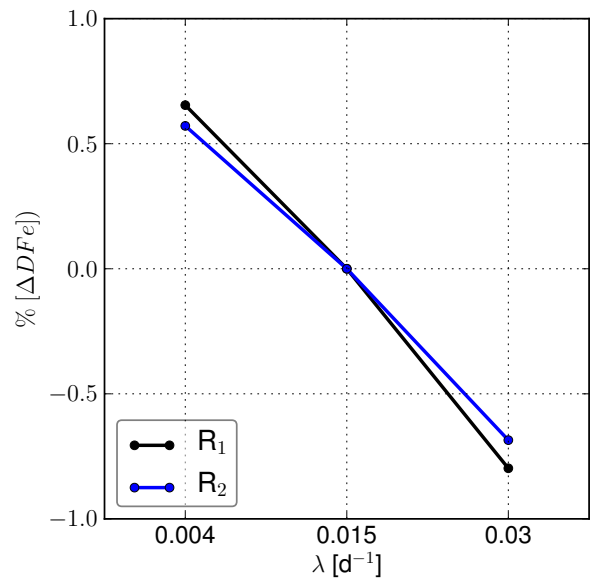

(a)

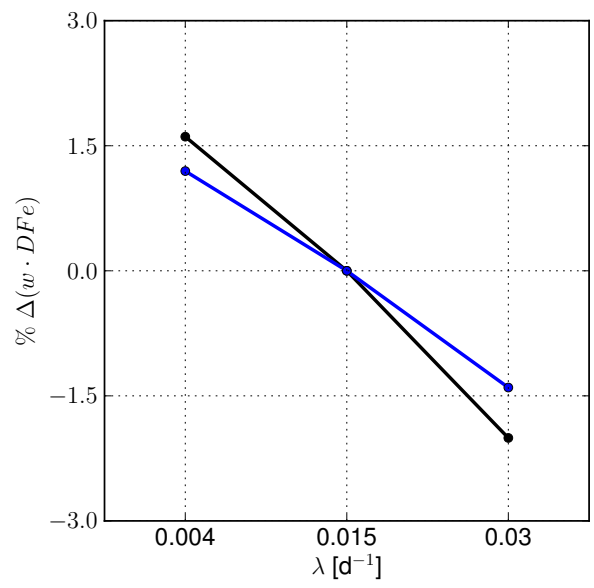

(c)

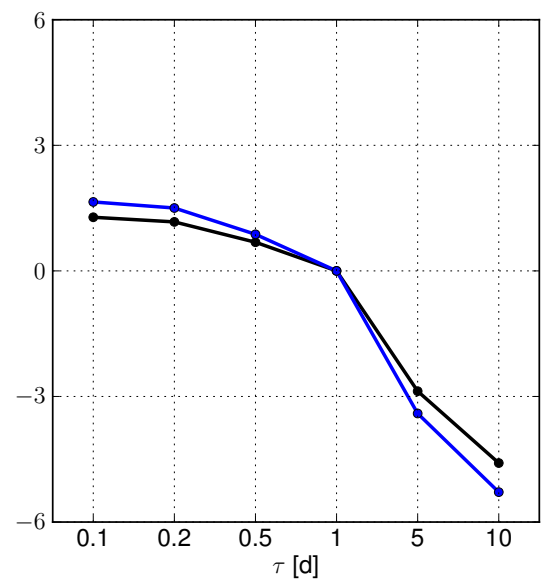

(b)

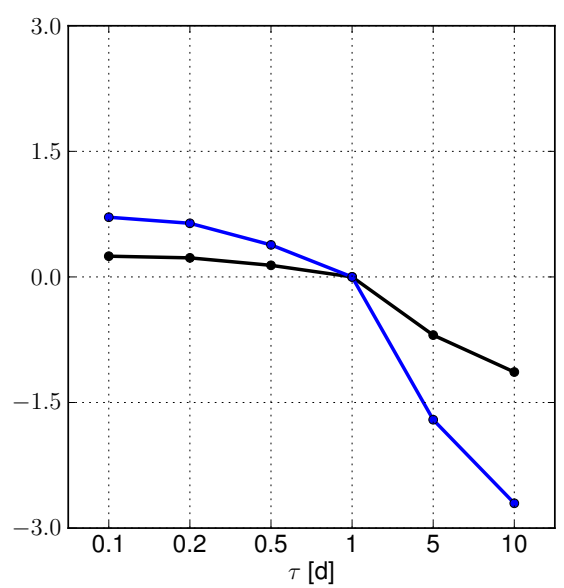

(d)

Figure 5: Sensitivity of dissolved iron concentration (a, b) and vertical iron fluxes (c, d) to decay rate $(\mathrm{a}, \mathrm{c})$ and relaxing timescale $(\mathrm{b}, \mathrm{d})$ for the particles in region $\mathrm{R}_{1}$ (black lines) and $\mathrm{R}_{2}$ (blue). Shown are results for the $1 / 80^{\circ}$ resolution experiment. The ordinate axis indicates the difference from the reference case, expressed as a percentage.

\section{Results}

Dissolved iron statistics are analysed with a focus on the sensitivity of total concentration of iron $[\mathrm{DFe}]$ and vertical fluxes of iron to the horizontal resolution. The goal of this analysis it to delineate the contribution that sub-mesoscale dynamics, resolved only by the $1 / 80^{\circ}$ resolution model, have over the supply of 
iron. Emphasis is given also to the impact of the resolution upon the sources of iron, for the two regions of study. To investigate the different iron sources, we delineate between $O N$ and $O F F$ particles, where $O N$ particles are those that reach the $O N$ plateau region during their lifetime. Conversely, the $O F F$ particles are defined as those that never touch the $O N$ region; for this analysis $O F F$ particles include those found in the transition zone (the $O N$ boundaries are defined in subsection 3.1.3).

In addition, we have found that a fraction of particles remains in the first $100 \mathrm{~m}$ of the water column. We note that the number of these particles decreases with the resolution: in the lowest resolution case we estimated that $18 \%$ of particles in $R_{1}$ and the $33 \%$ in $R_{2}$ do not go deeper than $100 \mathrm{~m}$, while only $13 \%$ of particles (in both $R_{1}$ and $R_{2}$ ) did not exceed $1000 \mathrm{~m}$ in the highest resolution case. These numbers are consistent with our findings (Fig. 3) that in the high resolution case there are more deep-reaching flows than at low resolution.

\subsection{Iron Concentration}

The average concentration of iron has been computed in the two regions and a representative case with $\lambda_{0}=0.015 \mathrm{day}^{-1}$ and $\gamma=1 \mathrm{day}^{-1}$ is shown in Fig. 6a. In this figure, red bars are used for the $1 / 20^{\circ}$ resolution case, while black indicates the $1 / 80^{\circ}$ resolution. [DFe] has been separated into the contribution from particles that move over the plateau $(O N)$ and particles that do not $(O F F)$. The magnitude of the dissolved iron concentration for the two sources is shown in Table 1.

The sensitivity of $[\mathrm{DFe}]$ to the resolution is evident from Fig. 6a, in both regions. In $\mathrm{R}_{1}, O N$ particles contribute $59 \%$ and $75 \%$ of the $[\mathrm{DFe}]$ in the low and high resolution case, respectively. The highest resolution case has slightly more $[D F e]$ (approximately $20 \mathrm{nmol} \mathrm{m}^{-3}$ ) than the $1 / 20^{\circ}$ resolution case and at both resolutions the simulated $[D F e]$ shows an enhancement respect to the $(90 \pm 34) \mathrm{nmol} \mathrm{m}{ }^{-3}$ of mean dissolved iron concentration observed by Blain et al. (2007) (estimated in the surface mixed layer both $O N$ and $O F F$ the plateau; dashed blue line in Fig. 6a). 


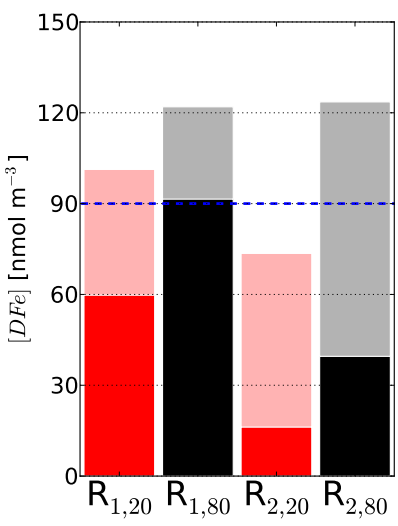

(a)

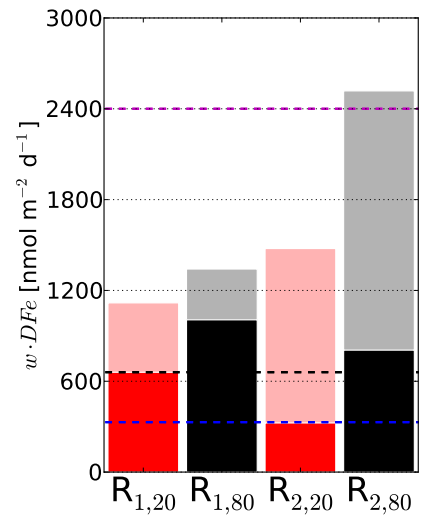

(b)

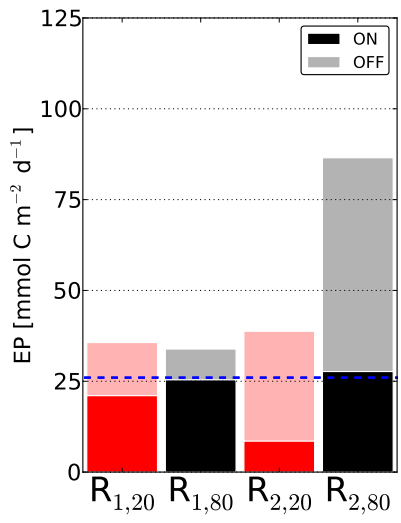

(c)

Figure 6: (a) Average dissolved iron concentration (particles released at both $75 \mathrm{~m}$ and $200 \mathrm{~m}$ are considered), (b) vertical fluxes of dissolved iron at $200 \mathrm{~m}$ and (c) export production estimated from the fluxes at $75 \mathrm{~m}$ for the two regions of analysis $\left(\mathrm{R}_{1}\right.$ and $\left.\mathrm{R}_{2}\right)$. Red (black) bars show the results for the $1 / 20^{\circ}\left(1 / 80^{\circ}\right)$ resolution model. The contribution due to the $O N$, $O F F$, as a proportion of the total number of particles, are indicated by the different shading. The blue dashed line in panel a indicates the $[D F e]$ over the plateau as observed by Blain et al. (2007). In panel b, the horizontal dashed lines identify estimates by Bowie et al. (2014): vertical flux due to upwelling (blue), total vertical flux due to the sum of diffusion, upwelling and entrainment (black) and lateral advective iron supply (magenta). Blue line in panel $\mathrm{c}$ is the observed net primary production observed in region $\mathrm{R}_{1}$ by Bowie et al. (2014).

In $\mathrm{R}_{2} O N$ particles account for $22 \%$ and $32 \%$ of the $[D F e]$ in the $1 / 20^{\circ}$ and $1 / 80^{\circ}$ resolution case, respectively. The greater contribution of the $O F F$ particles is consistent with the greater eddy activity in the vicinity of the region and its greater distance from the plateau. Again, the highest resolution simulation has more $[D F e]$ than the lowest resolution case (about $49 \mathrm{nmol} \mathrm{m}^{-3}$ ), but for this region the lowest resolution case has less DFe than observed (about 20\%) than Blain et al. (2007) estimates, while more at the highest (approximately $33 \%$ more).

\subsection{Vertical fluxes of DFe}

Vertical fluxes, computed for the case $\lambda_{0}=0.015$ day $^{-1}$ and $\gamma=1$ day $^{-1}$, are shown in Fig. 6b. We focus our investigation on the flux into the base of the mixed layer; hence, only the upward fluxes into the $200 \mathrm{~m}$ layer are here 


\begin{tabular}{|c|c|c|c|c|c|c|}
\hline Resolution & $\mathrm{R}_{1, T O T}$ & $\mathrm{R}_{1, O N}$ & $\mathrm{R}_{1, O F F}$ & $\mathrm{R}_{2, T O T}$ & $\mathrm{R}_{2, O N}$ & $\mathrm{R}_{2, O F F}$ \\
\hline \multicolumn{7}{|c|}{ Concentration of iron averaged between $75 \mathrm{~m}$ and $200 \mathrm{~m}\left[\mathrm{nmol} \mathrm{m}^{-3}\right]$ : } \\
\hline $1 / 20^{\circ}$ & 100 & 59 & 41 & 73 & 16 & 57 \\
\hline $1 / 80^{\circ}$ & 120 & 90 & 30 & 122 & 39 & 83 \\
\hline \multicolumn{7}{|c|}{ Vertical fluxes of iron estimated at $75 \mathrm{~m}\left[\mathrm{nmol} \mathrm{m} \mathrm{m}^{-2} \mathrm{~d}^{-1}\right]$ : } \\
\hline $1 / 20^{\circ}$ & 749 & 442 & 307 & 814 & 179 & 635 \\
\hline $1 / 80^{\circ}$ & 711 & 533 & 178 & 1816 & 581 & 1235 \\
\hline \multicolumn{7}{|c|}{ Vertical fluxes of iron estimated at $200 \mathrm{~m}\left[\mathrm{nmol} \mathrm{m} \mathrm{m}^{-2} \mathrm{~d}^{-1}\right]$ : } \\
\hline $1 / 20^{\circ}$ & 1106 & 653 & 453 & 1449 & 319 & 1130 \\
\hline $1 / 80^{\circ}$ & 1299 & 974 & 325 & 2472 & 791 & 1681 \\
\hline \multicolumn{7}{|c|}{ Export productivity estimated at $75 \mathrm{~m}\left[\mathrm{mmol} \mathrm{C} \mathrm{m}^{-2} \mathrm{~d}^{-1}\right]$ : } \\
\hline $1 / 20^{\circ}$ & 36 & 21 & 15 & 39 & 9 & 30 \\
\hline $1 / 80^{\circ}$ & 34 & 25 & 9 & 87 & 28 & 59 \\
\hline \multicolumn{7}{|c|}{ Total productivity estimated at $75 \mathrm{~m}\left[\mathrm{mmol} \mathrm{C} \mathrm{m}^{-2} \mathrm{~d}^{-1}\right]$ : } \\
\hline $1 / 20^{\circ}$ & 73 & 43 & 30 & 79 & 17 & 62 \\
\hline $1 / 80^{\circ}$ & 69 & 51 & 18 & 177 & 57 & 120 \\
\hline
\end{tabular}

Table 1: Dissolved iron concentration, vertical iron fluxes and estimated production for the two regions of analysis, due to TOT, ON and $O F F$ particles, and at the two resolutions. The export production estimates (EP) are computed from a $D F e / C$ ratio of $0.021 \mathrm{mmol} \mathrm{Fe} \mathrm{mol}^{-1} C$ (from Bowie et al., 2014), and then converted into total production using an fe ratio of 0.49 (from Sarthou et al., 2008).

presented. The sensitivity to the horizontal resolution of upwelling iron fluxes is, as for the $[D F e]$, more dramatic in $\mathrm{R}_{2}$ than in $\mathrm{R}_{1}$. We note that the vertical flux in the second region is larger by a factor of 2 in the $1 / 80^{\circ}$ case, while the flux at the highest resolution in $\mathrm{R}_{1}$ is just $15 \%$ larger. The values of upward vertical fluxes due to the different sources in presented are Table 1.

To put these values into context, we compare them with estimates of upwelling fluxes by Bowie et al. (2014). We are able to compare only region $\mathrm{R}_{1}$ with their "plume" stations. Here, the authors found a maximum vertical flux of $330 \mathrm{nmol} \mathrm{m}{ }^{-2} \mathrm{~d}^{-1}$ (indicated by a blue horizontal line in Fig. 6b), that, compared to our measurements, is smaller by a factor of 3.3 in the $1 / 20^{\circ}$ resolution case and of 4 in the $1 / 80^{\circ}$. Bowie et al. (2014) estimated also a maximum total vertical supply of dissolved iron (due to upwelling, diffusion and entrainment) 
of $661 \mathrm{nmol} \mathrm{m} \mathrm{m}^{-2} \mathrm{~d}^{-1}, 1.7$ times smaller than our estimate of iron fluxes (due to only upwelling) at the $1 / 20^{\circ}$ resolution. In the high resolution case our physical DFe supply is nearly double the estimate of Bowie et al. (2014), but it is still significantly less than Bowie et al. (2014) estimate of atmospheric and sediment supply.

\subsection{Primary production estimates}

To estimate the export production in the two regions we consider two calculations: vertical supply of iron to the euphotic zone (i.e. at $75 \mathrm{~m}$; equation 6 ) and a biological uptake computed using the decay rate (equation 9). Then, we use a $\mathrm{DFe} / \mathrm{C}$ ratio to convert the estimate into an estimate for carbon export (EP). $\mathrm{DFe} / \mathrm{C}$ is the mixed layer cellular uptake ratio, as observed in the "plume" region by Bowie et al. (2014) and estimated as $(0.021 \pm 0.002) \mathrm{mmol} \mathrm{Fe} \mathrm{mol}^{-1} C$.

The export based on the vertical supply of iron is given by:

$$
\frac{w \cdot D F e}{D F e / C}
$$

At $75 \mathrm{~m}$, and in the release location, we estimate an export primary production of $(36 \pm 3)$ mmol $\mathrm{C} \mathrm{m}^{-2} \mathrm{~d}^{-1}$ in $\mathrm{R}_{1}$ for the $1 / 20^{\circ}$ resolution model and of $(34 \pm 3) \mathrm{mmol} \mathrm{C} \mathrm{m}^{-2} \mathrm{~d}^{-1}$ at $1 / 80^{\circ}$ resolution. Given an absence of observed values in $R_{2}$, we use the same conversion ratio for this region and find that at the lowest resolution its export primary production is approximately (39 \pm 8$) \mathrm{mmol} \mathrm{C} \mathrm{m}^{-2} \mathrm{~d}^{-1}$, whereas it is $(87 \pm 8) \mathrm{mmol} \mathrm{C} \mathrm{m}^{-2} \mathrm{~d}^{-1}$ in the highest resolution case. Fig. 6c shows the estimates of EP, per region, resolution and source of particles. The blue line represents an observed EP (localised in region $\mathrm{R}_{1}$ ) of approximately $(26 \pm 1) \mathrm{mmol} \mathrm{C} \mathrm{m}^{-2} \mathrm{~d}^{-1}$ computed from the downward particulate iron export of $(541 \pm 216) \mathrm{nmol} \mathrm{m}^{-2} \mathrm{~d}^{-1}$ of Bowie et al. (2014). Estimates of the simulated EP relative to each source are reported in Table 1.

In $R_{1}$ the EP is about a third above the observed value at each resolution. In region $R_{2}$ we note an increase of more than a factor of 2 in the EP due to the resolution. Here, we cannot compare to any estimates, although we would 
expect EP in region $R_{2}$ to be similar or less than $R_{1}$ because $R_{2}$ is further away from KP than $\mathrm{R}_{1}$.

The estimated export productivity can be converted into total primary productivity by using the fe ratio, equal to the uptake of new iron/uptake of new + regenerated iron, of 0.49 (Sarthou et al., 2008). In region $R_{1}$ we find a total primary productivity of approximately $73 \mathrm{mmol} \mathrm{C} \mathrm{m}^{-2} \mathrm{~d}^{-1}$ and $69 \mathrm{mmol} \mathrm{C} \mathrm{m}^{-2} \mathrm{~d}^{-1}$ at $1 / 20^{\circ}$ and $1 / 80^{\circ}$ resolution, respectively. In $\mathrm{R}_{2}$ the estimated values are $78 \mathrm{mmol} \mathrm{C} \mathrm{m}^{-2} \mathrm{~d}^{-1}\left(1 / 20^{\circ}\right)$ and $177 \mathrm{mmol} \mathrm{C} \mathrm{m}^{-2} \mathrm{~d}^{-1}\left(1 / 80^{\circ}\right)$. This last value compares to an observed PP estimates in $\mathrm{R}_{1}$ of $132 \mathrm{mmol} \mathrm{C} \mathrm{m} \mathrm{m}^{-1}$. Total primary productivity estimates for the $O N$ and $O F F$ particles are shown in the last row of Table 1 . In $\mathrm{R}_{1}$ our estimate of vertical $D F e$ supply is 1.3 more than what is required to meet the estimated particulate iron export. In R2 our estimate is 1.5 to 3.3 times the estimated particulate iron export.

While our simulated vertical iron supply is an upper bound particularly at $\mathrm{R}_{2}$, the supply due to sub-mesoscale processes is substantial, approaching the value estimate for iron supply from the sediments on the KP and is much greater than the estimated export.

However, we highlight that the computation of export production based on upward iron fluxes gives a maximum estimate, as physical flows can transport iron downward as well. Hence, we can calculate the biological export of iron at the base of the euphotic layer $\left(z^{*}\right)$ as the flux required to balance the loss of iron by biological consumption $(S(z))$ :

$$
S(z)-\frac{\partial \phi_{F e}(z)}{\partial z}=0
$$

$\phi_{F e}(z)$ represents the vertical flux of iron and its value at $z=z^{*}$ can be obtained by integrating (7) over the euphotic layer:

$$
\phi_{F e}\left(z^{*}\right)=-\int_{z^{*}}^{0} S(z) d z
$$

The consumption $S(z)$ is given by the first term in the right hand side of equation 
(1):

$$
S(z)=-\lambda(z) D F e(z)
$$

424

where $\lambda(z)$ is given by $(2)$. We can therefore obtain a general formulation for the biological export of iron:

$$
\phi_{F e}\left(z^{*}\right) \sim \lambda_{0} \delta\left[\frac{\delta}{z^{*}}\left(e^{z^{*} / \delta}-1\right)-1\right] \operatorname{DFe}\left(z^{*}\right) .
$$

In our model we use $z^{*}=-75 \mathrm{~m}$ and $\delta=35 \mathrm{~m}$. The biological export of iron in (9) can be then converted into export production using the $\mathrm{Fe} / \mathrm{C}$ ratio and total production using the fe ratio. We find that at $1 / 20^{\circ}$ resolution the total production accounts for approximately $7 \mathrm{mmol} \mathrm{C} \mathrm{m}^{-2} \mathrm{~d}^{-1}$ in $\mathrm{R}_{1}$ and $3 \mathrm{mmol} \mathrm{C} \mathrm{m} \mathrm{m}^{-1}$ in $\mathrm{R}_{2}$, while at $1 / 80^{\circ}$ we estimate $9 \mathrm{mmol} \mathrm{C} \mathrm{m}^{-2} \mathrm{~d}^{-1}$ and $10 \mathrm{mmol} \mathrm{C} \mathrm{m}^{-2} \mathrm{~d}^{-1}$ in $\mathrm{R}_{1}$ and $\mathrm{R}_{2}$, respectively.

While these numbers are much smaller than the upwelled supply of iron estimated above (from equation 6) they still account for the significant portion of measured iron EP. In $R_{1}$, vertical physical supply accounts for about a third of the estimate particulate iron export $(26 \pm 1)$ mmol $\mathrm{C} \mathrm{m}^{-2} \mathrm{~d}^{-1}$. In this region adjacent to the KP the horizontal supply of iron is more important consistent with previous observations. In the $1 / 80^{\circ}$ resolution $R_{2}$, the estimate iron export is nearly a half the measured export. In this region resolving the sub-mesoscale vertical supply of iron is important and could be the dominant mechanism of iron supply.

\section{Discussion and Conclusions}

FeRRO $_{S O}$ represents an innovative technique for the study of specific processes affecting iron concentration in iron-limited waters, such as the Southern Ocean. The model has been applied to a framework that does not incorporate the contribution of diffusive mechanisms as our motivation was to specifically investigate the impact of sub-mesoscale advection on the supply of iron. FeRRO $_{S O}$ has just two parameters, decay and replenishment time-scales, chosen 
to represent bio-geochemical processes not explicitly resolved in $\mathrm{FeRRO}_{S O}$. We show these two parameters have a weak effect on the final estimates of iron concentration and fluxes. This insensitivity to parameters is due to the timescale of the upward/downward advection of the particles in the upper $100 \mathrm{~m}$ of the water column being shorter than the iron decay timescale. Also, in case of the replenishment timescale $\tau$, which we have varied over two orders of magnitudes, we have not found a significant difference in the behaviour of FeRRO $S O$. Thus we conclude that $\mathrm{FeRRO}_{S O}$ is robust and that it does not depend on the choice of parameters.

While the results presented above are not sensitive to the choice of the parameters, they do depend on the location of investigation and on the horizontal resolution of the numerical model. This sensitivity reflects the different dynamics resolved by the simulations, which are also strongly affected by the location of analysis (Rosso et al., 2015). We have shown that iron concentration, fluxes and primary productivity are comparable in region $\mathrm{R}_{1}$, where the sub-mesoscale activity is weak (Rosso et al., 2014). Conversely, in region $\mathrm{R}_{2}$, where the submesoscale dynamics are the most active (Rosso et al., 2014), we simulate an increase in iron estimates with the horizontal resolution, demonstrating that sub-mesoscale processes have an impact on the transport of dissolved iron. We note that sub-mesoscale particles are more likely to reach depths (Fig. 3), where $[D F e]$ is enhanced. It follows that as sub-mesoscales reach greater depths and rapidly transport waters to the surface (Rosso et al., 2014), they can transport a higher concentration of dissolved iron.

At $R_{1}$ we estimate a vertical iron supply that is slightly greater than the observed value reported in Bowie et al. (2014), but varies little with resolution. Moreover, here the vertical supply is less than a third the estimate for horizontal advection of iron from the KP. We confirm that in this region the dominant contribution to the supply of iron is most likely due to lateral processes. $R_{1}$ is closer to $\mathrm{KP}$ than $\mathrm{R}_{2}$, which might explain the larger impact of the lateral supply.

Our results suggest that in $\mathrm{R}_{2}$ the vertical supply is a first order mechanism 
for the supply of iron. Furthermore, as the vertical flux increases with the resolution, we conclude that iron supply in this region is likely to be predominantly due to sub-mesoscale upwelling of dissolved iron. However, we are not able to compare our estimated iron supply of $\mathrm{R}_{2}$ with any observed estimates. Following Mongin et al. (2009) we can expect a smaller lateral advection into this region (as they found that the lateral supply decays with the distance from the plateau). We find that the vertical iron supply, approaches the estimated value for the horizontal advection of $D F e$ in $\mathrm{R}_{1}$. Furthermore, using the calculation from the decay rate (equations 2 and 9) we find that the simulated EP accounts for about a half the measured EP. This calculation requires an assumption that EP from $R_{1}$ can be used for $R_{2}$ which may not strictly hold; the observed EP most likely provides an upper estimate.

From the large difference in the $1 / 80^{\circ}$ vertical fluxes between the two regions (almost 2-fold), a similar difference in the concentration could be expected. Yet, the difference in the concentration is just about $2 \%$. The reason is likely due to a combination of downward iron flux (which may be as large as the upward component) and biological uptake.

The recent work of d'Ovidio et al. (2015) presents a similar technique in the estimate of iron supply to the phytoplankton plume downstream of the plateau. They apply a Lagrangian approach, based on surface altimetry velocities. Furthermore, they use an iron decay model, representing scavenging. The model is comparable to the decay term of our model (first term on the right hand side of equation 1). In their estimate, the decay constant $\lambda=0.051 \pm 0.006$ day $^{-1}$ is well comparable to our larger value of $\lambda_{0}=0.03$ day $^{-1}$. Their estimates for the supply flux in the plume $\left(2400 \pm 600 \mathrm{nmol} \mathrm{m}^{-2}\right.$ day $^{-1}$ in October-November and $1700 \pm 400 \mathrm{nmol} \mathrm{m}^{-2}$ day $^{-1}$ for January-February) are also comparable to our estimates (Table 1 and Fig. 6). In their work, the supply is purely horizontal and based on the horizontal distance from the plateau. Instead, our methodology comprises also the estimate of a supply rate, that depends on location and source depth. The advantage of our approach is that, by including the vertical dynamics, we are able to estimate the impact of the small-scale circulation in the 
supply of iron. We conclude that a model like ours could serve to inform a study such as that presented by d'Ovidio et al. (2015), when observations cannot provide information about vertical dynamics. Furthermore, the strong comparison in the fluxes estimates strengthens the robustness of our methodology.

We highlight that in our numerical simulations no seasonal cycle has been modelled and, therefore, $\mathrm{FeRRO}_{S O}$ estimates are purely indicative of a mean state. It would be of great interest for the scientific community to investigate how the seasonal variation can affect the iron supply, however this is beyond the scope of the present work. Furthermore, a future development should include a more realistic implementation of bio-geochemical processes.

We conclude that sub-mesoscale dynamics can affect the near-surface budgets of dissolved iron concentration and export production, by enhancing the vertical advective fluxes of dissolved iron concentration in Southern Ocean conditions. We suggest that sub-mesoscale fluxes need to be parameterised in coarser resolution models for the quantification of iron budgets; however, these parameterisations need to take into account the complex spatial variations present in sub-mesoscale dynamics.

\section{Acknowledgments}

A. Hogg was supported by Australian Research Council Future Fellowship FT120100842. We want to express our thanks to A. Bowie for constructive discussions. 


\section{References}

Abraham, E. R., Law, C. S., Boyd, P. W., Lavender, S. J., Maldonadok, M. T., Bowie, A. R., 2000. Importance of stirring in the development of an ironfertilized phytoplankton bloom. Nature 407, 727-730.

Archer, D., Johnson, K., 2000. A model of the iron cycle in the ocean. Global Biogeochem. Cycles 14 (1), 269-279.

Blain, S., Queguiner, B., Armand, L., Belviso, S., Bombled, B., Bopp, L., Bowie, A., Brunet, C., Brussaard, C., Carlotti, F., Christaki, U., Corbiere, A., Durand, I., Ebersbach, F., Fuda, J.-L., Garcia, N., Gerringa, L., Griffiths, B., Guigue, C., Guillerm, C., Jacquet, S., Jeandel, C., Laan, P., Lefevre, D., Lo Monaco, C., Malits, A., Mosseri, J., Obernosterer, I., Park, Y.-H., Picheral, M., Pondaven, P., Remenyi, T., Sandroni, V., Sarthou, G., Savoye, N., Scouarnec, L., Souhaut, M., Thuiller, D., Timmermans, K., Trull, T., Uitz, J., van Beek, P., Veldhuis, M., Vincent, D., Viollier, E., Vong, L., Wagener, T., 2007. Effect of natural iron fertilization on carbon sequestration in the Southern Ocean. Nature 446, 1070-1074.

Bowie, A. R., van der Merwe, P., Quéroué, F., Trull, T., Fourquez, M., Planchon, F., Sarthou, G., Chever, F., Townsend, A. T., Obernosterer, I., Sallée, J.-B., Blain, S., 2014. Iron budgets for three distinct biogeochemical sites around the Kerguelen archipelago (Southern Ocean) during the natural fertilisation experiment KEOPS-2). Biogeosc. Discuss., 1786117923.

Boyd, P. W., Watson, A. J., Law, C. S., Abraham, E. R., Trull, T., Murdoch, R., Bakker, D. C. E., Bowie, A. R., Buesseler, K. O., Chang, H., Charette, M., Croot, P., Downing, K., Frew, R., Gall, M., Hadfield, M., Hall, J., Harvey, M., Jameson, G., LaRoche, J., Liddicoat, M., Ling, R., Maldonado, M. T., McKay, R. M., Nodder, S., Pickmere, S., Pridmore, R., Rintoul, S., Safi, K., Sutton, P., Strzepek, R., Tanneberger, K., Turner, S., Waite, A., Zeldis, J., 2000. A mesoscale phytoplankton bloom in the polar Southern Ocean stimulated by iron fertilization. Nature 407 (6805), 695-702. 
Bucciarelli, E., Blain, S., Tréguer, P., 2001. Iron and manganese in the wake of the Kerguelen Islands (Southern Ocean). Mar. Chem. 73 (1), 21-36.

Chever, F., Sarthou, G., Bucciarelli, E., Blain, S., Bowie, A. R., et al., 2010. An iron budget during the natural iron fertilisation experiment KEOPS (Kerguelen Islands, Southern Ocean). Biogeosc. 7, 455-468.

Coale, K. H., Johnson, K. S., Chavez, F. P., Buesseler, K. O., Barber, R. T., Brzezinski, M. A., Cochlan, W. P., Millero, F. J., Falkowski, P. G., Bauer, J. E., et al., 2004. Southern Ocean iron enrichment experiment: carbon cycling in high- and low-Si waters. Science 304 (5669), 408-414.

De Baar, H. J., Boyd, P. W., Coale, K. H., Landry, M. R., Tsuda, A., Assmy, P., Bakker, D. C., Bozec, Y., Barber, R. T., Brzezinski, M. A., et al., 2005. Synthesis of iron fertilization experiments: from the iron age in the age of enlightenment. J. Geophys. Res. 110 (C9).

d'Ovidio, F., De Monte, S., Della Penna, A., Cotté, C., Guinet, C., 2013. Ecological implications of eddy retention in the open ocean: A Lagrangian approach. J. Phys. A: Math. Theor. 46 (25), 254023.

d'Ovidio, F., Della Penna, A., Trull, T., Nencioli, F., Pujol, I., Rio, M., Park, Y.H., Cotté, C., Zhou, M., Blain, S., 2015. The biogeochemical structuring role of horizontal stirring: Lagrangian perspectives on iron delivery downstream of the Kerguelen plateau. Biogeosciences Discussions 12 (1), 779-814.

Ducklow, H. W., Steinberg, D. K., Buesseler, K. O., 2001. Upper ocean carbon export and the biological pump. Oceanogr. 14 (4), 50-58.

Gille, S., Carranza, M., Cambra, R., Morrow, R., 2014. Wind-induced upwelling in the Kerguelen Plateau Region. Biogeosc. 11, 6389-6400.

Gregg, W. W., Ginoux, P., Schopf, P. S., Casey, N. W., 2003. Phytoplankton and iron: validation of a global three-dimensional ocean biogeochemical model. Deep Sea Research Part II: Topical Studies in Oceanography 50 (22), 31433169 . 
Khatiwala, S., Primeau, F., Hall, T., 2009. Reconstruction of the history of anthropogenic $\mathrm{CO}_{2}$ concentrations in the ocean. Nature 462 (7271), 346-349.

Lévy, M., Klein, P., Tréguier, A.-M., 2001. Impact of sub-mesoscale physics on production and subduction of phytoplankton in an oligotrophic regime. J. Mar. Res. 59, 535-565.

Maraldi, C., Mongin, M., Coleman, R., Testut, L., 2009. The influence of lateral mixing on a phytoplankton bloom: Distribution in the Kerguelen Plateau region. Deep Sea Res. Part I 56, 963-973.

Marshall, J., Adcroft, A., Hill, C., Perelman, L., Heisey, C., 1997. A finitevolume, incompressible Navier Stokes model for studies of the ocean on parallel computers. J. Geophys. Res. 102 (C3), 5753-5766.

Marshall, J., Speer, K., 2012. Closure of the meridional overturning circulation through southern ocean upwelling. Nat. Geosc. 5 (3), 171-180.

Martin, J. H., 1990. Glacial-interglacial $\mathrm{CO}_{2}$ change: The iron hypothesis. Paleoceanogr. 5 (1), 1-13.

Mayewski, P. A., Meredith, M., Summerhayes, C., Turner, J., Worby, A., Barrett, P., Casassa, G., Bertler, N. A., Bracegirdle, T., Naveira Garabato, A., et al., 2009. State of the Antarctic and Southern Ocean climate system. Rev. Geophys. 47 (1).

Mazloff, M. R., Heimbach, P., Wunsch, C., 2010. An Eddy-Permitting Southern Ocean State Estimate. J. Phys. Oceanogr. 40 (5), 880-899.

McCartney, M. S., Donohue, K. A., 2007. A deep cyclonic gyre in the AustralianAntarctic Basin. Progr. Oceanogr. 75 (4), 675-750.

Mongin, M., Molina, E., Trull, T. W., 2008. Seasonality and scale of the Kerguelen plateau phytoplankton bloom: A remote sensing and modeling analysis of the influence of natural iron fertilization in the Southern Ocean. Deep Sea Res. Part II 55, 880-892. 
Mongin, M. M., Abraham, E. R., Trull, T. W., 2009. Winter advection of iron can explain the summer phytoplankton bloom that extends $1000 \mathrm{~km}$ downstream of the Kerguelen Plateau in the Southern Ocean. J. Mar. Res. 67, $225-237$.

Paris, C. B., Helgers, J., van Sebille, E., Srinivasan, A., 2013. Connectivity Modeling System: A probabilistic modeling tool for the multi-scale tracking of biotic and abiotic variability in the ocean. Environ. Modell. Softw. 42, $47-54$.

Park, Y.-H., Durand, I., Kestenare, E., Rougier, G., Zhou, M., d'Ovidio, F., Cotté, C., Lee, J.-H., 2014. Polar Front around the Kerguelen Islands: An upto-date determination and associated circulation of surface/subsurface waters. J. Geophys. Res. 119 (10), 6575-6592.

Park, Y.-H., Fuda, J.-L., Durand, I., Garabato, N., Alberto, C., 2008. Internal tides and vertical mixing over the Kerguelen Plateau. Deep Sea Res. Part II $55(5-7), 582-593$.

Rosso, I., Hogg, M. A., Kiss, E. A., Gayen, B., 2015. Topographic influence on sub-mesoscale dynamics in the Southern Ocean. Geophys. Res. Lett. 42.

Rosso, I., Hogg, M. A., Strutton, G. P., Kiss, E. A., Matear, R., Klocker, A., van Sebille, E., 2014. Vertical transport in the ocean due to sub-mesoscale structures: Impacts in the Kerguelen region. Ocean Modell. 80, 10-23.

Sarthou, G., Vincent, D., Christaki, U., Obernosterer, I., Timmermans, K. R., Brussaard, C. P., 2008. The fate of biogenic iron during a phytoplankton bloom induced by natural fertilisation: Impact of copepod grazing. Deep Sea Res. Part II 55 (5), 734-751.

Sigman, D. M., Hain, M. P., Haug, G. H., 2010. The polar ocean and glacial cycles in atmospheric $\mathrm{CO}_{2}$ concentration. Nature 466 (7302), 47-55. 
Tagliabue, A., Sallée, J.-B., Bowie, A. R., Lévy, M., Swart, S., Boyd, P. W., 2014. Surface-water iron supplies in the Southern Ocean sustained by deep winter mixing. Nat. Geosci. 7 (4), 314-320.

Takahashi, T., Sweeney, C., Hales, B., Chipman, D. W., Newberger, T., Goddard, J. G., Iannuzzi, R. A., Sutherland, S. C., 2012. The changing carbon cycle in the Southern Ocean. Oceanogr. 25 (3), 26-37.

Talley, L. D., 2013. Closure of the global overturning circulation through the Indian, Pacific, and Southern Oceans: Schematics and transports. Oceanogr. $26(1), 80-97$.

Van Beek, P., Bourquin, M., Reyss, J.-L., Souhaut, M., Charette, M., Jeandel, C., 2008. Radium isotopes to investigate the water mass pathways on the Kerguelen Plateau (Southern Ocean). Deep Sea Res. Part II 55 (5), 622-637. 